\title{
Transport and persistence of drifting macroalgae (Rhodophyta) are strongly influenced by flow velocity and substratum complexity in tropical seagrass habitats
}

\author{
Patrick D. Biber* \\ Department of Marine Biology and Fisheries, Rosenstiel School of Marine and Atmospheric Science, University of Miami, \\ 4600 Rickenbacker Causeway, Miami, Florida 33129, USA \\ Present address: The University of Southern Mississippi, Gulf Coast Research Laboratory, 703 East Beach Drive, \\ Ocean Springs, Mississippi 39564, USA
}

\begin{abstract}
Currents induced by tidal circulation and wind in shallow tropical seagrass habitats can influence the distribution of drifting macroalgae. In Florida, drift algae are mostly comprised of 5 to 10 genera of Rhodophyta (red algae), with 1 or 2 dominant species. Drift clump transport was investigated through manipulative experiments. Increasing flow velocities entrained and transported clumps of drift algae; transport speeds were 50 to $67 \%$ of flow velocity and did not vary statistically significantly between clump sizes tested. The roughness of the substratum influenced transport speeds, with moderate to dense monospecific turtlegrass Thalassia testudinum reducing the speed of transport compared to bare substratum. Mixed seagrass substrata ( $T$. testudinum and Halodule wrightii) further inhibited transport of drift clumps by more frequent entangling compared to the bare and monospecific substrata. Persistence of drift algae was inversely related to flow conditions, with longer persistence at low flow velocities.
\end{abstract}

KEY WORDS: Rhodophyta $\cdot$ Drift algae $\cdot$ Seagrass $\cdot$ Circulation $\cdot$ Landscape $\cdot$ Transport

\section{INTRODUCTION}

Hydrodynamic flow is not only a direct environmental factor affecting seagrasses and macroalgae but it also influences other limiting factors such as nutrient availability, light penetration (turbidity), and temperature and salinity stratification (Lobban \& Harrison 1994). The development of communities of unattached macroalgae is promoted under conditions that are commonly found in calm coastal waters (Norton \& Mathieson 1983); in the tropics these are often dominated by benthic seagrass habitats. In Florida seagrass systems, clumps of drift macroalgae vary in size (10 to $40 \mathrm{~cm}$ diameter) and are typically comprised of rhodophyte (red algal) taxa (Virnstein \& Carbonara 1985, Holmquist 1997, Bell \& Hall 1997).
Drift algae in Biscayne Bay, Florida, originate primarily from epiphytes growing in situ on seagrass blades, e.g. Polysiphonia, Chondria (Norton \& Mathieson 1983, Bell \& Hall 1997); however some species can also be found growing on hard substrata located adjacent to seagrass beds, e.g. Laurencia, Sargassum (Biber 2002, Lirman et al. 2003). Regardless of the original source, drift algae can be moved via tidal currents and wind-induced water motion. Passive movement of drift algae suggests that the flow velocities near and in a seagrass patch may determine the distribution of areas of macroalgal retention or accumulation. Flow is reduced with increasing distance from the patch edge, as well as in the lee of the patch (Fonseca et al. 1983, Fonseca \& Koehl 2006). Low-flow areas associated with seagrass patches affect landscape structure (Fon- 
seca \& Bell 1998) and can influence accumulation of drift algae (Bell \& Hall 1997).

Bell \& Hall (1997) found that spatial variation in drift distribution was highly correlated with the local energy regime in Tampa Bay, with passive transport and deposition of algal clumps strongly linked to the bay-wide hydrodynamic regime. In that shallow system, algal movement was heavily dictated by waves (wind-driven and boat wakes) and currents, with hydrodynamically less active environments favoring accumulation of drift algae at a greater rate than sites with high current velocity or extensive exposure to waves (Bell \& Hall 1997). This exposure regime resulted in landscape-level accumulations of drift algae within certain portions of Tampa Bay where energy was low.

At the local scale, drift algae display highly aggregated distributions within seagrass beds. Some seagrass beds may retain more drift algae then others because of blade morphology (Virnstein \& Carbonara 1985); thus, the spatial distribution of algae may be closely linked to seagrass species composition and spatial distribution of seagrass patches. Transport of drift algae within seagrass was found to be greatest in shallow-water beds with short canopies during periods of wind-induced waves or tidal currents (Madley \& Bell 1996). Higher amounts of drift biomass (3.5 to 18.5 times as much) were found in large seagrass patches compared to smaller patches, in accordance with patterns expected if algae accumulate in zones of attenuated water flow (Bell et al. 1995). Differences in algal accumulation may also be related to the location of source populations relative to seagrass patches, patch orientation relative to flow, and the route of dispersal between these positions (flow direction and magnitude).

This study investigated the mechanisms by which tidal currents entrain and transport drift algae, the potential persistence time of a clump of drift on different seagrass species, and the implications of these processes on the potential landscape distribution of drift macroalgae found in tropical seagrass beds, using Biscayne Bay, Florida, as an example. To test the hypothesis that flow velocity of tidal currents affects drift algal transport and persistence time, the following questions were addressed:
- What tidal velocities are required to entrain and transport clumps of drift algae?

- Does substratum roughness of different seagrass species influence transport rates?

-What is the persistence time of drift algae under different flow regimes?

\section{MATERIALS AND METHODS}

Expt 1: drift transport and persistence under variety of flow regimes. Manipulative experiments were conducted near the University of Miami's Rosenstiel School of Marine and Atmospheric Science (RSMAS) boat dock located in Bear Cut (BRC; Fig. 1), to determine the ability of natural tidal flows to entrain and transport clumps of drift algae. Bear Cut, like many other cuts between barrier islands on the eastern side of Biscayne Bay, has a significant tidal flow from the Atlantic Ocean to the Bay. With semi-diurnal

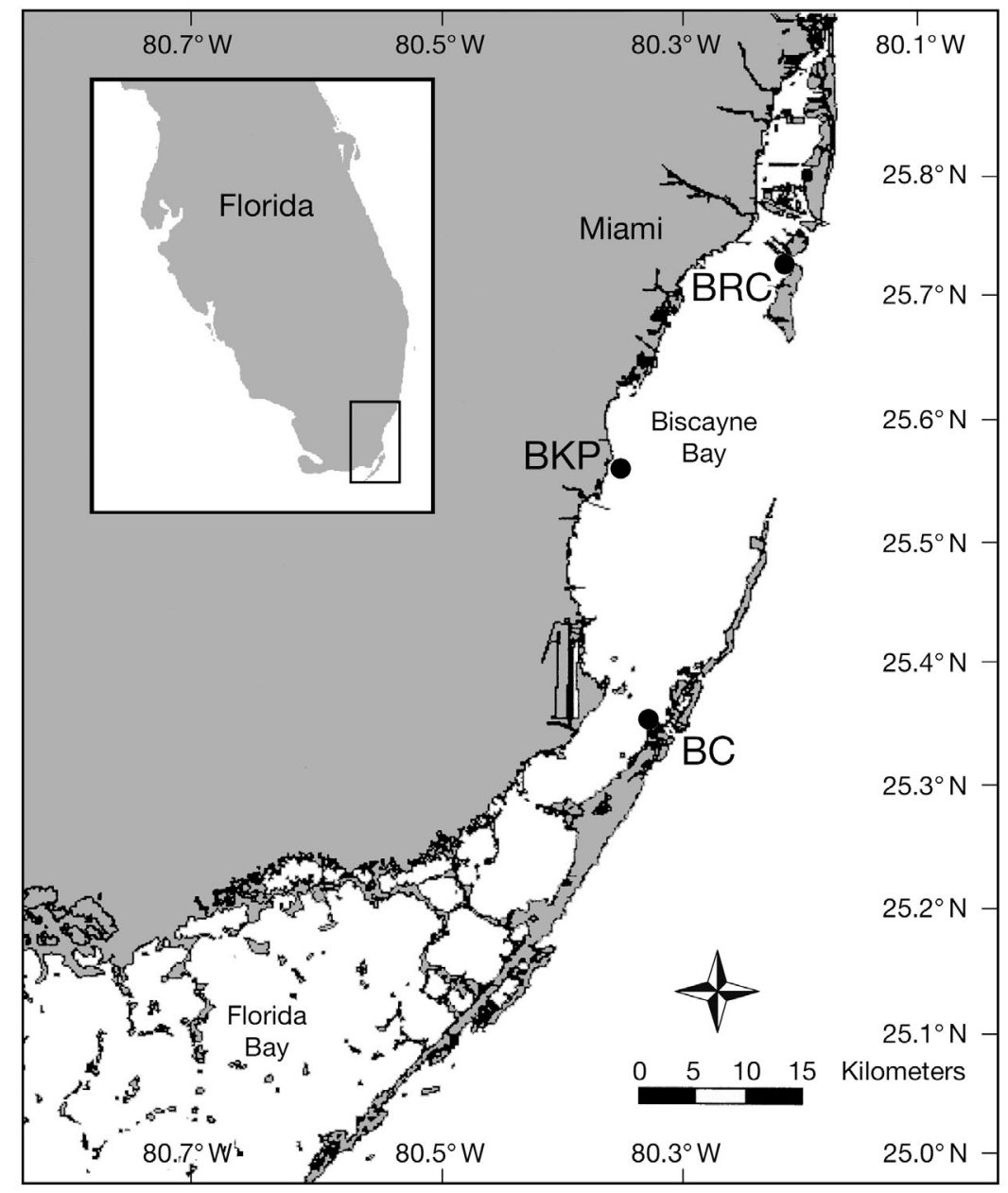

Fig. 1. Location of study sites in Biscayne Bay, Florida. BKP: Black Point; BC: Broad Creek; BRC: Bear Cut 
tides, the RSMAS docks are subjected to strong currents (50 to $70 \mathrm{~cm} \mathrm{~s}^{-1}$ ) 4 times each day through this inlet ( $\mathrm{T}$. Jones pers. comm.).

Transport of drift algae under 2 tidal-flow regimes was experimentally tested in a seagrass bed located near the RSMAS docks. The bed is located between 10 and $20 \mathrm{~m}$ offshore (MTL) and within 5 and $10 \mathrm{~m}$ of the docks. Flow velocities were determined at peak incoming tide and approximately half flood-tide using a rotary flow-meter (Model 2030, General Oceanics); 5 replicate measurements were made, each of $5 \mathrm{~min}$ duration, at each stage of the tide. Transport rates of clumps of drift algae of a known biomass, either 100 or $500 \mathrm{~g}$ (spun for $3 \mathrm{~min}$ to remove excess water in a salad spinner: Hay 1981) were measured at 2 current velocities ( 50 and $25 \mathrm{~cm} \mathrm{~s}^{-1}$ ) by recording the transit time over $1 \mathrm{~m}$ distance. Drift clumps were composed of a mix of the 2 dominant genera found in Biscayne Bay, Laurencia spp. and Chondria spp.; material was collected from drifting algae captured in a seine net near the study site. Five replicate measurements of transport time were taken, and Student's $t$-tests were performed comparing clump sizes at a given current velocity.

Persistence times of drift algae under 3 flow regimes were compared in $0.25 \mathrm{~m}^{2}$ plots in summer. A highflow and medium-flow regime were set up in the seagrass bed; open plots (= high-flow, $\mathrm{n}=5$ ) were marked at 4 corners by metal stakes pushed into the sediment and enclosed plots (= medium-flow, $\mathrm{n}=5$ ) were created using $2.5 \mathrm{~cm}$ Vexar mesh tied to the metal stakes, effectively reducing current by about half. A no-flow control $(n=5)$ was set up in a large flow-through seawater mesocosm with an established seagrass substratum, with very similar depth, light, temperature, water quality, and seagrass shoot density to the field plots, the exception being absence of currents. Flow measurements $(\mathrm{n}=3)$ using the General Oceanics rotary flow-meter for 5 min per measurement, were taken at each plot on the day before algae were added and a 1-way ANOVA was performed on the measured current speeds.

Approximately $1 \mathrm{~kg}$ spun wet weight of drift algae (approximately 50\% Laurencia spp., 50\% Chondria spp.) was added to each of the 10 plots at slack low tide. The plots were revisited at the end of the first flood tide $(6 \mathrm{~h})$; all algae in the open plots had been removed by the current. Remaining biomass (spun wet wt) of drift algae in the enclosures was measured daily at low tide, with remaining algal biomass replaced after weighing, until no more algae were present (5d). The influence of flow on persistence of the remaining biomass was analyzed by repeated-measures ANOVA, with time treated as a blocking variable (Neter et al. 1996). The potential for drift algae to persist in the absence of tidal flow was observed in the mesocosm during the summer (August) and winter (February) as temperature may influence persistence.

Expt 2: drift transport rates over various seagrass substrata. A rapidly deployable flume was built out of a half cylinder of clear acrylic $(1.2 \mathrm{~m}$ long $\times 15 \mathrm{~cm}$ diameter) attached to glass sides (30 cm high) and placed over 4 different seagrass substrata: sparse, medium, and dense Thalassia testudinum, and dense mixed T. testudinum and Halodule wrightii in the previously mentioned seagrass mesocosms, where these plants had been growing for over 2 yr (see Table 1 for densities). Recirculating flow within the flume was provided by a $189 \mathrm{l} \mathrm{min}^{-1}$ submersible pump (Model 6-CIA, Little Giant Pump Co.), regulated by a $2.5 \mathrm{~cm}$ PVC ball valve to control the flow rate. Flow velocities used were determined by recording the time it took a front of red dye (Red Food Color, McCormick \& Co.) to traverse the length of the flume at the seagrass canopy level.

A clump of mixed Laurencia/Chondria spp. drift algae (about $100 \mathrm{~g}$ spun wet wt) was placed in the flume through a moveable glass panel next to the incoming nozzle and diffuser and transit times were measured ( $\mathrm{n}=3$ to 7 ) under 4 different flow velocities $\left(0,7.5,25\right.$, and $\left.55 \mathrm{~cm} \mathrm{~s}^{-1}\right)$. Data were plotted as algal transport speed against current velocity in the flume for each of the 4 seagrass substratum types. Data were analyzed using the Sheirer-Ray-Hare extension of the non-parametric Kruskal-Wallis test, followed by Tukey's post-hoc comparisons to determine like groups (Sokal \& Rohlf 1995).

\section{RESULTS}

\section{Expt 1: drift transport and persistence under variety of flow regimes}

Flow velocities were statistically significantly different among the 3 flow regimes measured in the field (one-way Model I ANOVA: $F_{2,17}=83.501, \mathrm{p}<0.0001$ ). Flows measured during peak flood tidal currents in Bear Cut were close to $50 \mathrm{~cm} \mathrm{~s}^{-1}$. Mean flood tide velocities were about $60 \%$ higher than ebb tide flows (Fig. 2A). The presence of the $2.5 \mathrm{~cm}$ Vexar mesh enclosures reduced flows by about half, resulting in mean peak flood current velocities experienced by the drift algae within the enclosures of 20 to $25 \mathrm{~cm} \mathrm{~s}^{-1}$ (Fig. 2A). Flows in the no-flow mesocosm were zero.

Transport speeds of 2 different sizes of drift algal clumps released over the Bear Cut (BRC) seagrass bed were between 50 and $75 \%$ current velocity (Fig. 2B), with no statistically significant differences among clump sizes (at $25 \mathrm{~cm} \mathrm{~s}^{-1}: t_{4 \mathrm{df}}=1.235, \mathrm{p}=0.2846$; and at $50 \mathrm{~cm} \mathrm{~s}^{-1}: t_{4 \mathrm{df}}=-0.373, \mathrm{p}=0.7281$ ). 
Table 1. Characteristics of mesocosm seagrass (Thalassia testudinum and Halodule wrightii) habitats over which the flume was used, for the two quadrats in each flume. Number of seagrass shoots $0.25 \mathrm{~m}^{-2}$ is given, as well as approximate canopy height; -: not tested

\begin{tabular}{|c|c|c|c|}
\hline \multirow[t]{2}{*}{ Grass cover } & \multicolumn{2}{|c|}{ No. of shoots } & \multirow{2}{*}{$\begin{array}{c}\text { Canopy } \\
\text { height }(\mathrm{cm})\end{array}$} \\
\hline & T. testudinum & H. wrightii & \\
\hline \multirow{2}{*}{ Very sparse } & 9 & - & 30 \\
\hline & 8 & - & 30 \\
\hline \multirow[t]{2}{*}{ Medium } & 62 & - & 45 \\
\hline & 63 & - & 45 \\
\hline \multirow[t]{2}{*}{ Dense } & 91 & - & 45 \\
\hline & 76 & - & 45 \\
\hline \multirow[t]{2}{*}{ Dense mixed } & 61 & 24 & 55 \\
\hline & 69 & 58 & 55 \\
\hline
\end{tabular}

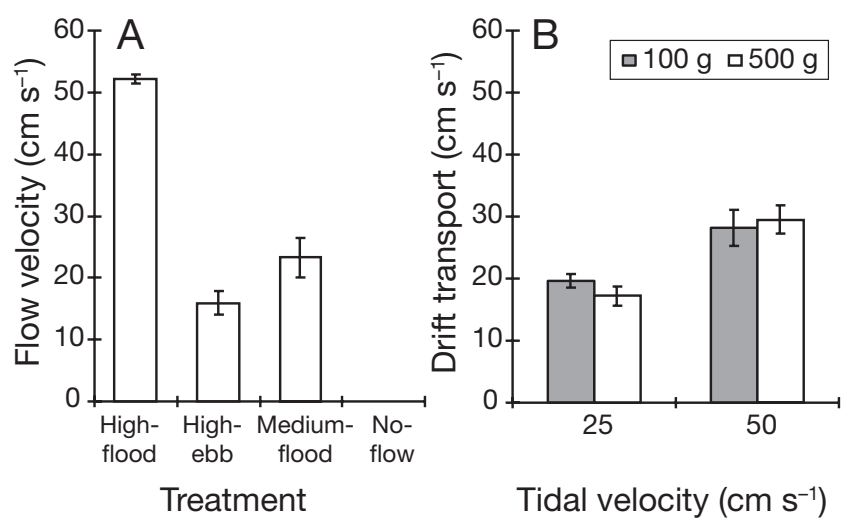

Fig. 2. Results of Expt 1 field transport trials. (A) Mean $( \pm \mathrm{SE})$ flow velocities measured within seagrass bed (high, medium) and in mesocosm (no-flow). (B) Mean $( \pm \mathrm{SE}$ ) transport speeds of 2 different sizes of drift algal clumps in Bear Cut seagrass bed
The persistence time of drift algae in the 3 flow regimes differed statistically significantly (Table 2), with persistence time inversely related to flow velocity (Fig. 3A). In the high-flow regime (the open plots) persistence time was less than 1 tide. Observations of drift algae placed in the canopy of the seagrass bed in Bear Cut showed that algal clumps were entrained by the tidal current once flow velocities approached $10 \mathrm{~cm} \mathrm{~s}^{-1}$, and then rapidly transported out of the open plots at flow velocities exceeding $20 \mathrm{~cm} \mathrm{~s}^{-1}$. Algae placed in the enclosed plots persisted for up to $5 \mathrm{~d}$ (about 20 tidal cycles), with biomass decreasing exponentially as the clumps were successively fragmented (Fig. 3A).

Drift algae persisted in the no-flow conditions for about 1 mo in the summer, with a steady decline (Fig. 3B). The decrease in biomass appeared to be related to the loss of thallus tissues in the high summer time water temperatures $\left(>30^{\circ} \mathrm{C}\right)$. To test this, the trial was repeated in winter, when water temperatures are frequently less than $25^{\circ} \mathrm{C}$. Drift algae in the mesocosms persisted longer in winter than in summer, although there was no statistically significant difference in biomass over time (Fig. 3B, Table 2). Decline in biomass in winter was observed to be primarily a result of the mats becoming positively buoyant because of trapped bubbles from photosynthesis, and floating to the surface of the mesocosm tank, with some loss occurring down the drains of the tank. A substantial portion of this floating biomass was inadvertently discarded in routine maintenance activities of the mesocosm facility around Day 25, when 3 of the 5 replicate tanks were cleared of all remaining drift biomass and the experiment was terminated. For these reasons, the persistence time recorded for the winter is highly conservative, observed to be on the order of 1.5 to 2 mo, compared to around 1 mo in the summer (Fig. 3B).
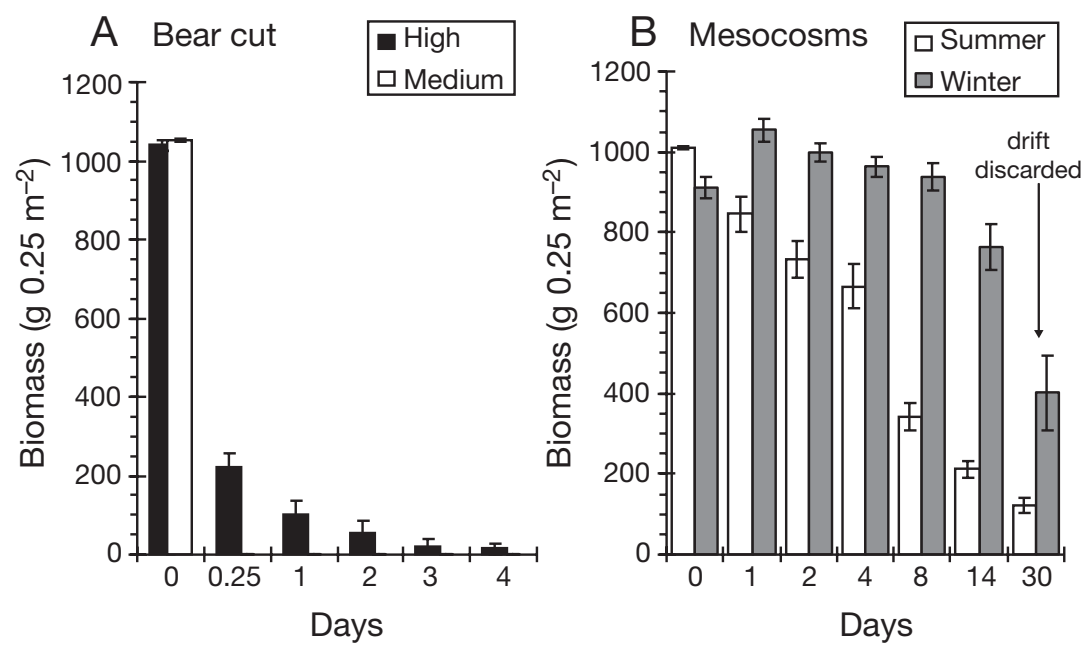

Fig. 3. Drift biomass remaining from Expt 1. (A) Persistence times of drift algae under 2 flow regimes, high and medium. (B) Differences between 2 seasons (summer and winter) in no-flow regime in mesocosms

\section{Expt 2: drift transport rates over various seagrass substrata}

In the flume, transport speeds of the drift algal clumps increased statistically significantly with increasing flow velocity across all 4 substratum types tested (Table 3, p < 0.001). However, increasing density and canopy height of seagrass substrata resulted in decreases in drift transport speed for a given flow velocity (Fig. 4); seagrass surface complexity inversely influenced transport speed. For all flow velocities, drift transport over the very sparse substratum was 
Table 2. Repeated-measures ANOVA on persistence of drift biomass in the 3 flow regimes (fixed factor) $\times$ time (fixed blocking factor) during summer trial (Flow $\times$ Time), and repeatedmeasures ANOVA on season (fixed factor) $\times$ time (fixed blocking factor) for no-flow regime in mesocosms (Season $\times$ Time) (see Fig. 2)

\begin{tabular}{|c|c|c|c|c|c|}
\hline Source & df & SS & MS & $F$ & $\mathrm{p}$ \\
\hline \multicolumn{6}{|c|}{ Flow $\times$ Time $\left(\right.$ ANOVA $\left.r^{2}=0.8614, \mathrm{n}=5\right)$} \\
\hline Flow & 2 & 3762820 & 1881410 & \multirow[t]{3}{*}{6.736} & \multirow[t]{3}{*}{$<0.05$} \\
\hline Day & 3 & 6651299 & 2217099 & & \\
\hline Error & 6 & 1675791 & 279298.5 & & \\
\hline \multicolumn{6}{|c|}{ Season $\times$ Time $\left(\right.$ ANOVA $\left.r^{2}=0.8562, n=5\right)$} \\
\hline Season & 1 & 1197317 & 1197317 & \multirow[t]{3}{*}{4.907} & \multirow[t]{3}{*}{$<0.10$} \\
\hline Day & 7 & 8969468 & 1281353 & & \\
\hline Error & 7 & 1708035 & 244005 & & \\
\hline
\end{tabular}

always greater than over the medium and dense seagrass, with drift transport speed close to the flow velocity (Fig. 4). At $7.5 \mathrm{~cm} \mathrm{~s}^{-1}$ there was no difference in drift transport speed over the medium and the 2 dense seagrass substrata (Fig. 4). When flow velocity increased to $25 \mathrm{~cm} \mathrm{~s}^{-1}$, both the medium and dense Thalassia testudinum substratum slowed drift transport somewhat, compared to the very sparse substratum (Fig. 4). Observations of the T. testudinum seagrass blades during these experiments showed that as water velocity increased, the blades were increasingly pushed over, so that at high flows most blades were parallel to the substratum, forming in essence a 'bare' substratum condition with little chance of the grass entangling the drift clump.

In contrast, at $25 \mathrm{~cm} \mathrm{~s}^{-1}$ transport speed was statistically significantly slower in the mixed seagrass bed than either the medium or dense Thalassia testudinum substratum (Table 3, p < 0.001), because of the Halodule wrightii sheaths projecting into the water column,

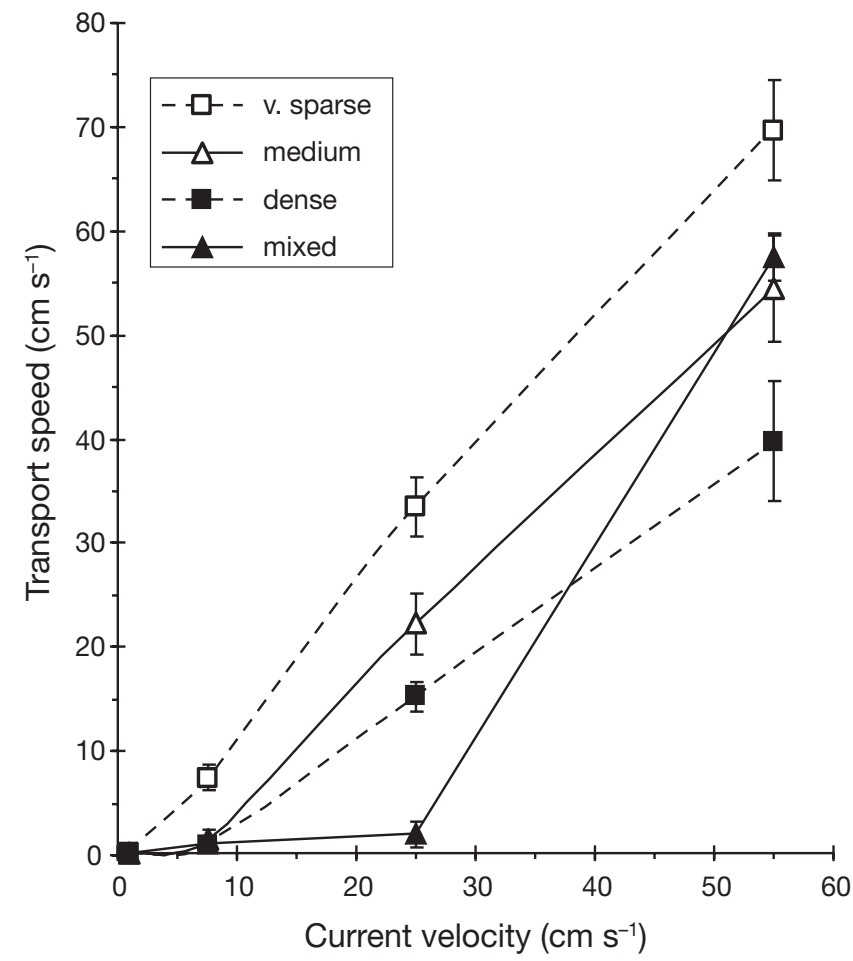

Fig. 4. Mean $( \pm \mathrm{SD})$ drift algae transport rates under increasing flow velocities in a flume placed over 3 densities of Thalassia testudinum: very sparse ( $<10$ shoots), medium (60 to 65$)$, dense (>75); and a dense mixed T. testudinum and Halodule wrightii substratum (see Table 1)

causing the drift algae to become entangled. At the highest flow velocity $\left(55 \mathrm{~cm} \mathrm{~s}^{-1}\right)$ this phenomenon did not occur as frequently, as the velocity of the water column was fast enough to deter settling of the clumps, thereby reducing the possibility of algal entrapment by $H$. wrightii. Additionally, even the $H$. wrightii sheaths tended to bend at the highest flow velocity, further reducing the possibility of drift algae becoming snared as they tumbled over the seagrass bed.
Table 3. Sheirer-Ray-Hare extension of non-parametric Kruskal-Wallis test on drift transport rates $\times$ flow velocity and substratum type (both fixed factors) presented in Fig. 4. Appropriate chi-square test is SS/MS total (Sokal \& Rohlf 1995). Statistically significant results at $\alpha=0.05$ are in bold. Tukey's post-hoc comparison of significant results indicates significant differences among flow treatments

\begin{tabular}{|lcrrrc|}
\hline Source & df & \multicolumn{1}{c|}{ SS } & \multicolumn{1}{c|}{ MS } & \multicolumn{1}{c|}{$\chi^{2}$} & \multicolumn{1}{c|}{ p } \\
\hline Substratum (S) & 3 & 542.063 & 180.688 & 5.6347 & $<0.10$ \\
Flow (F) & 2 & 3362.042 & 1681.021 & 34.9478 & $<\mathbf{0 . 0 0 1}$ \\
F $\times$ S & 6 & 217.625 & 36.271 & 2.2622 & $<0.75$ \\
error & 36 & 399.750 & 11.104 & & \\
total & 47 & 4521.480 & 96.202 & & \\
Flow & $7.5 \mathrm{~cm} \mathrm{~s}^{-1}$ & $25 \mathrm{~cm} \mathrm{~s}^{-1}$ & $50 \mathrm{~cm} \mathrm{~s}^{-1}$ & $\mathbf{A}$ & \\
Tukey & $\mathbf{C}$ & $\mathbf{B}$ & $\mathbf{A}$ & \\
& & \multicolumn{5}{c}{} \\
\hline
\end{tabular}

\section{DISCUSSION}

Increasing flow velocities reduced the persistence time of drift algae within the seagrass bed in Expt 1. In Bear Cut, in sparse seagrass beds with short canopies, drift clumps were often removed from the bed within $24 \mathrm{~h}$ by currents. Clumps entangled in the canopy of dense seagrass did not readily move, with residence times of up to $4 \mathrm{~d}$. In a similar study in Florida Bay, only $15 \%$ of clumps were moved in seagrass beds with 
low flow velocities, whereas $95 \%$ of clumps were transported over bare substratum under moderate to strong flows (Holmquist 1994). Export of clumps that were not initially entangled in the seagrass was greater, with $85 \%$ moving more than $100 \mathrm{~m}$, and in some cases up to $500 \mathrm{~m}$ in $24 \mathrm{~h}$ (Holmquist 1994). Tidal currents could dislodge and transport enmeshed algal clumps from seagrass beds a distance of at least 50 m over 20 d (Holmquist 1994).

Current velocity was an important determinant of drift algal transport (cf. Bell \& Hall 1997). Higher current velocities were required to remove clumps of algae that were entrapped within the seagrass canopy than clumps that were resting on the canopy surface. This was evident in the different observations on clumps in the flume (introduced over the canopy) compared to clumps entrapped in the seagrass leaves in the Bear Cut experiment. The threshold velocity was observed to be around $10 \mathrm{~cm} \mathrm{~s}^{-1}$ before the tidal current was forceful enough to dislodge the drift algae from the seagrass patch.

Once dislodged, transport speeds of drift algal clumps in this study were somewhat higher than previously reported by Holmquist (1994) from Florida Bay. The roughness and species composition of seagrass beds affected the transport rates of drift clumps in the flume experiments. Transport rates of drift algae over seagrass were nonlinear with increasing current velocity. At low to intermediate flow velocities, drift algae were transported over seagrass at reduced speed compared to over bare substratum. However, an increase in transport speeds at the higher flow velocities occured over dense seagrass, comparable to those over bare substrata. Thalassia testudinum has a morphology such that at increasing flow velocities the blades bend over and create in essence a 'smooth surface' similar to a bare substratum. Holmquist $(1994,1997)$ found that high densities and flexibility of $T$. testudinum blades allow algal clumps being tumbled along by currents to roll over the flattened canopy of blades, at speeds similar to those over bare substrata.

In the presence of moderate to fast currents ( $>15$ to $20 \mathrm{~cm} \mathrm{~s}^{-1}$ ) over seagrass, clumps of Laurencia spp. were transported by slowly tumbling over the bottom, rather than drifting in a fixed orientation. Clump movement was sporadic; drifting occurred for a few minutes before clumps settled and became enmeshed in the seagrass. After a while, clumps broke free and resumed drifting. Algal clumps typically tumbled along at, or just above, the surface of the bare sand or seagrass canopy. At the highest flow velocity tested $\left(55 \mathrm{~cm} \mathrm{~s}^{-1}\right)$ the drift algal clumps were entrained in the water column and rarely contacted the substratum as they were moved along by the current.
Drift algae can originate from macroalgae growing in situ, attached to hard substrata or seagrass plants, or fragmenting off epiphytes growing on seagrass blades and other drift clumps (Phillips 1960, Hamm \& Humm 1976, Josselyn 1977). A number of species that commonly comprise the drift algae (e.g. Laurencia spp.) are not usually observed as epiphytes on seagrass blades (Phillips 1960, Hamm \& Humm 1976, Williams-Cowper 1978), suggesting in situ growth on suitable substrates or possible external provenance from adjacent hardbottom reef areas within Biscayne Bay (Lirman et al. 2003). However, most species of rhodophytes (e.g. Chondria spp., Cladophora spp. Polysiphonia spp.) found within the seagrass beds studied were not abundant elsewhere and probably originated as seagrass epiphytes (Biber 2002). For both species growing in situ in the seagrass, as well as drift species like Sargassum spp. that are clearly derived from external sources, a mechanism is required to explain the transport of this drift material. Currents from tidal water exchange in Biscayne Bay, and wind- or wave-induced water movement are the most parsimonious factors likely to affect the distribution of drift algae.

The spatial distribution of unattached benthic drift algae can become highly aggregated because of tidal and wind-induced circulation currents (Josselyn 1977, Williams-Cowper 1978, Virnstein \& Carbonara 1985), resulting in a high degree of temporal and spatial patchiness within Biscayne Bay. Accumulations of drift algae tens of centimeters thick can cover large areas, while adjacent areas contain virtually no drift algae; this has also been reported in the Indian River Lagoon (Kulczycki et al. 1981, Virnstein \& Carbonara 1985). Accumulations of high densities of drift algae in Biscayne Bay occurred most often where seagrass growth was not well developed (i.e. bare patches, boat propeller scars), especially on the down-current sides of seagrass patches as a consequence of reduced current speeds (Williams-Cowper 1978, Zieman et al. 1989).

The spatial distribution of drift algae depends on the interplay of local- and landscape-scale effects on current velocity. At the small spatial scale (meters) within a site, water motion and current flow may not always be directly related to the accumulation of drift algae, with abiotic and biotic factors (nutrients, grazing, light) being important variables affecting algal biomass. At the mesoscale (10s to 100 s of meters), accumulation of drift algae occurs when currents are locally reduced enough to allow deposition (like the lee of a bank, or depressions where current flow is reduced), or if obstructions entangle passing clumps of algae. At the landscape scale $(\mathrm{km})$, it is the interaction of tidal and wind-induced currents and the spatial arrangement of seagrass patches that influence whether a location can be a potential sink or source of drift material. 
For instance in Biscayne Bay, Black Point (BKP) is a site that experiences low flow conditions and had consistent accumulations of drift algae, while Broad Creek (BC), a site of more rapid current flow, did not (Biber 2002, Irlandi et al. 2004). Even so, at BC, clumps of algae were often observed drifting across the site, and obstructions such as PVC posts marking monitoring locations, or more commonly, sponges, soft corals, or clumps of the rhizophytic alga Halimeda opuntia were routinely observed to capture large mats of algae. Regular monitoring of drift biomass at these 2 sites indicated that despite the observed transport of drift algal clumps at BC, there was little long-term accumulation (Irlandi et al. 2004). The opposite was found to be true at BKP, where little transport of drift algae was observed, but where there was extensive persistent biomass year round (Irlandi et al. 2004). This difference in the abundance of drift algae at these 2 sites may also be a result of the source of the drift algae. Many of the species that make up the drift algae at BKP originate in situ as epiphytes growing attached to seagrass leaves (Biber 2002, Irlandi et al. 2004). As they increase in biomass, and as the seagrass leaves senesce and are sloughed from the shoots, the formerly epiphytic algae become part of the drift community.

The results of my 2 experiments indicate the potential for drift algal accumulation in low-energy environments, such as those that occur along the mainland coastline of Biscayne Bay. Accumulation is dependent upon both small-scale factors such as substratum type, or large-scale factors like the presence of low-velocity 'sinks' associated with vegetated seagrass substrata. In Biscayne Bay, drift accumulations in the low-velocity seagrass sites along the mainland may be exacerbated by elevated nutrient concentrations ( $\mathrm{N}$ and $\mathrm{P}$ ) brought in by drainage canals (Alleman et al. 1995). Similar nutrient-induced proliferations of macroalgae have been demonstrated to have adverse impacts on seagrass abundance and condition elsewhere (Hauxwell et al. 2001).

In this study I have demonstrated that drift algae are readily transported by tidal currents, and drift along at speeds between one-half and two-thirds the ambient current velocity. Transport speed is a function of substratum type, as more complex bottom topography increases the possibility of entanglement, thereby reducing transport rates. Tidal currents and wave energy have the potential to influence the landscape distribution of drift algae; however, local factors including nutrients and grazing may confound this.

Acknowledgements. This research was funded by the US Army Corps of Engineers (DACW39-94-K-0032) and NOAA Coastal Ocean Program (NA37RJO149) awards to M. A. Harwell and the Center for Marine and Environmental Analyses at the University of Miami. The manuscript benefited from comments by A. Uhrin, C. Rakocinski, and R. Virnstein. Portions of this research were conducted to fulfill the requirements of a PhD dissertation at the University of Miami.

\section{LITERATURE CITED}

Alleman RW, Bellmund SA, Black DW, Formati SE, Gove CA, Gulick LK (1995) Biscayne Bay surface water improvement and management plan, technical supporting document. South Florida Water Management District, West Palm Beach, FL

Bell SS, Hall MO (1997) Drift macroalgal abundance in seagrass beds: investigating large-scale associations with physical and biotic attributes. Mar Ecol Prog Ser 147: $277-283$

Bell SS, MO Hall, Robbins BD (1995) Toward a landscape approach in seagrass beds: using macroalgal accumulation to address questions of scale. Oecologia 104:163-168

Biber PD (2002) The effects of environmental stressors on the dynamics of 3 functional groups of algae in Thalassia testudinum habitats of Biscayne Bay, Florida: a modeling approach. PhD dissertation, University of Miami, Coral Gables, FL

Fonseca M, Bell S (1998) Influence of physical setting on seagrass landscapes near Beaufort, North Carolina, USA. Mar Ecol Prog Ser 171:109-121

Fonseca M, Koehl M (2006) Flow in seagrass canopies: the influence of patch width. Estuar Coast Shelf Sci 67:1-9

Fonseca M, Zieman J, Thayer G, Fisher J (1983) The role of current velocity in structuring eelgrass (Zostera marina L.) meadows. Estuar Coast Shelf Sci 17:367-380

Hamm D, Humm HJ (1976) Benthic algae of the Anclote Estuary. 2. Bottom dwelling species. Fla Sci 39:209-229

Hauxwell J, Cebrian J, Furlong C, Valiela I (2001) Macroalgal canopies contribute to eelgrass (Zostera marina) decline in temperature estuarine ecosystems. Ecology 82:1007-1022

Hay ME (1981) Spatial patterns of grazing intensity on a Caribbean barrier reef: herbivory and algal distribution. Aquat Bot 11:97-109

Holmquist JG (1994) Benthic macroalgae as a dispersal mechanism for fauna: influence of a marine tumbleweed. J Exp Mar Biol Ecol 180:235-251

Holmquist JG (1997) Disturbance and gap formation in a marine benthic mosaic: influence of shifting macroalgal patches on seagrass structure and mobile invertebrates. Mar Ecol Prog Ser 158:121-130

Irlandi EA, Orlando BA, Biber PD (2004) Drift algae-epiphyte-seagrass interactions in a subtropical Thalassia testudinum meadow. Mar Ecol Prog Ser 279:81-91

Josselyn MN (1977) Seasonal changes in the distribution and growth of Laurencia poitei in a subtropical lagoon. Aquat Bot 3:217-229

Kulczycki GR, Virnstein RW, Nelson WG (1981) The relationship between fish abundance and algal biomass in a seagrass-drift algae community. Estuar Coast Shelf Sci 12: 341-347

Lirman D, Orlando B, Macia S, Manzello D, Kaufman L, Biber P, Jones T (2003) Coral communities of Biscayne Bay, Florida and adjacent offshore areas: diversity, abundance, distribution, and environmental correlates. Aquat Conserv: Mar Freshw Ecosys 13:121-135

Lobban CS, Harrison PJ (1994) Seaweed ecology and physiology. Cambridge University Press, Cambridge

Madley KA, Bell SS (1996) Characteristics which affect the movement of drifting macroalgae in a patchy seagrass 
shoal. In: Woodin SA, Allen DM, Stancyk SE (eds) Twentyfourth Annual Benthic Ecology Meeting, University of South Carolina, Columbia, SC, p 99

Neter J, Kutner MH, Nachtsheim CJ, Wasserman W (1996) Applied linear statistical models, 4th edn. Irwin, Chicago, IL Norton TA, AC Mathieson (1983) The biology of unattached seaweeds. Prog Phycol Res 2:333-386

Phillips RC (1960) Ecology and distribution of marine algae found in Tampa Bay, Boca Ciega Bay and at Tarpon Springs, Florida. Q J Fla Acad Sci 23:222-260

Sokal RR, Rohlf FJ (1995) Biometry. The principles and prac-

Editorial responsibility: Otto Kinne (Editor-in-Chief), Oldendorf/Luhe, Germany tice of statistics in biological research, 3rd edn. WH Freeman \& Co, New York

Virnstein RW, Carbonara PA (1985) Seasonal abundance and distribution of drift algae and seagrasses in the mid-Indian River lagoon, Florida. Aquat Bot 23:67-82

Williams-Cowper S (1978) The drift algae community of seagrass beds in Redfish Bay, Texas. Contrib Mar Sci 21: $125-132$

Zieman JC, Fourqurean JW, Iverson RL (1989) Distribution, abundance and productivity of seagrass and macroalgae in Florida Bay. Bull Mar Sci 44:292-311

Submitted: November 24, 2005; Accepted: January 30, 2007 Proofs received from author(s): July 23, 2007 